\title{
Modeling the length and shape of the R\&D lag: an application to UK agricultural productivity
}

\author{
Colin Thirtle $^{\mathrm{a}}$, Jenifer Piesse ${ }^{\mathrm{b}}$, David Schimmelpfennig ${ }^{\mathrm{c}, *}$
}

a Centre for Environmental Policy, Imperial College London, Exhibition Road, London SW7 2AZ, United Kingdom, and Department of Agricultural Economics, Extension and Rural

b Development, University of Pretoria, South Africa, Pretoria, South Africa Department of Management, King's College London, 150 Stamford Street, London SE1 9HN, United Kingdom, and University of Stellenbosch, Republic of South Africa, Stellenbosch, South Africa

c Economic Research Service, U.S. Department of Agriculture, 1800 M Street NW, Washington DC 20036-5831, USA

\section{Abstract}

This article updates total factor productivity (TFP) growth in UK agriculture from 1953-2005 and shows that public and private research and returns to scale explain TFP. Cointegration and causality tests are used to investigate the validity of attempts to explain UK agricultural productivity with $\mathrm{R} \& \mathrm{D}$ and related technology variables. Then, the length and shape of the lag structures are modeled and compared with the structures that are commonly imposed on the data. The rates of return (ROR) to R\&D using the data determined lags differ considerably from those obtained by imposing lag shapes. These comparisons show that the ROR to public R\&D are sensitive to the lag shape as well as its length and that the omission of other technology variables, such as mechanical and chemical patents pertaining to agriculture and farm size can bias the ROR.

\section{Introduction}

Changes in accounting procedures and index construction have substantially improved TFP measurement in UK agriculture. These changes are reviewed and summarized in Thirtle et al. (2004). The methodology is now very similar to that used by the United States Department of Agriculture (USDA) in constructing the US TFP statistics. Furthermore, the passage of time has added substantially to the length of the time series since Schimmelpfennig and Thirtle (1994) first applied time series techniques to these data. Thus, this article updates TFP in UK agriculture to 2005 and then explains TFP change using both time series techniques and data determined lag structures.

The next section briefly explains the data and reports the TFP results, which show that the UK has had very little TFP growth since the severe cuts in the R\&D budget that began in 1982. The TFP index is explained by technological progress, measured by both public R\&D and private patents. The third section checks the validity of the 
relationship between TFP and the explanatory variables by investigating the time series properties of the data, establishing that cointegrating regressions exist and establishing causality. Section four uses the time series data to model the length and shape of the R\&D lag, using beta, exponential, gamma, and polynomial lag distributions (PDL). The biases caused by omitting the patent variables that represent private technology generation are investigated. Then, in section five, the lag shape as well as the length, plus variable omission are shown to be important to the rate of return (ROR) estimates. This section illustrates that ignoring private sector patent activity can bias the ROR for public R\&D downward, rather than upward. The final section offers conclusions that speculate on this unexpected outcome and the current state of knowledge.

\section{Measuring and explaining TFP in UK agriculture}

There is no doubt that UK TFP growth in the last two decades has been slow and this is shown most clearly by international comparisons. Fig. 1 uses data from an unpublished study for the UK Department for the Environment, Food and Rural Affairs (DEFRA) by Eldon Ball. As recently as 1981, the UK was level with France, but French growth continued, while UK growth ceased, so that by 2001 there is a huge gap between the UK and the leading EU countries. Indeed, the UK is now the least productive country in the EU, along with Sweden. This would be unremarkable if it were not for the fact that the UK national agricultural research system is still quite highly regarded internationally. To find the cause of the demise in UK productivity this article follows the conventional wisdom in supposing that TFP growth is generated by technological change, which results from public and private R\&D, assisted by some contribution from increases in farm size, as there is the expectation of increasing returns to scale.

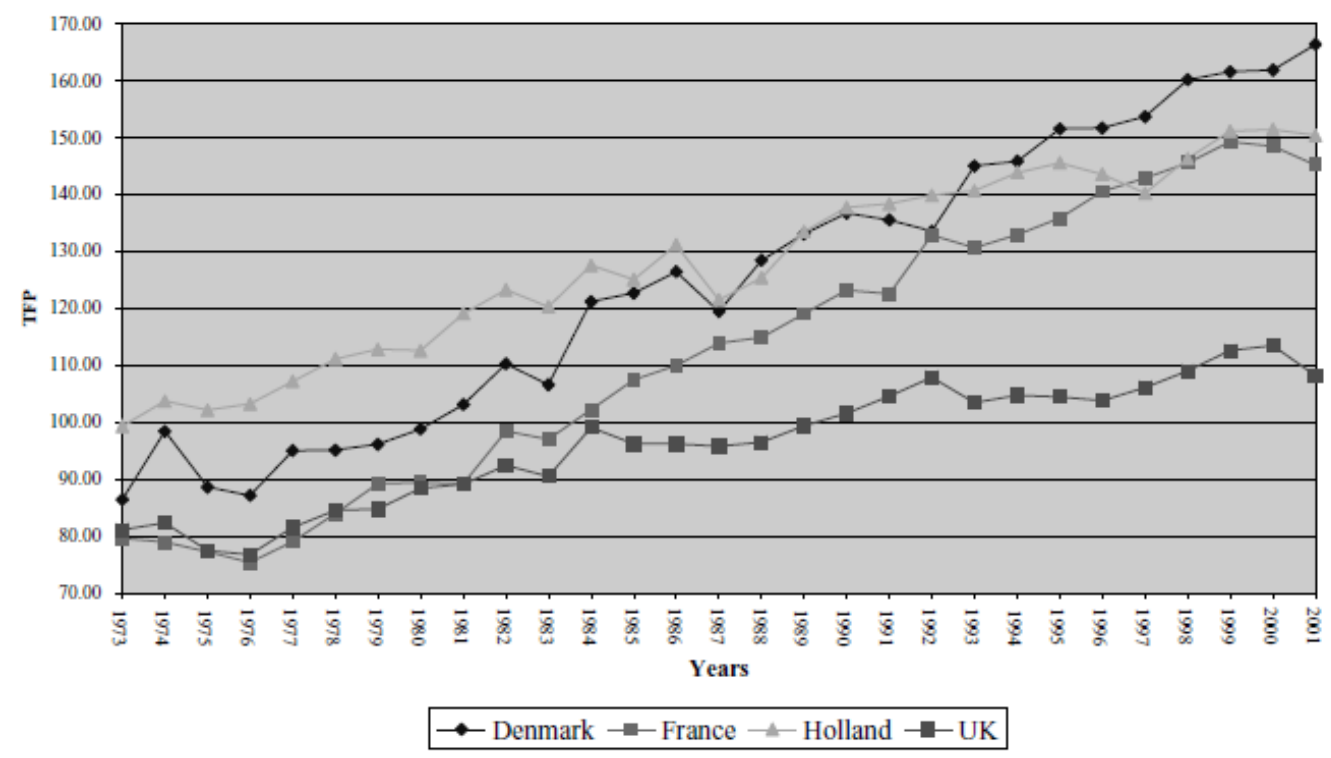

Fig. 1. TFPs for the leading EU countries and the UK.

Thirtle et al. (2004) reported on the construction of a new Tornqvist-Theil TFP index for the UK agricultural sector, which is very similar in construction to the index 
reported by the USDA. DEFRA has adopted the same methods, except that it reports Fisher's ideal index, but this makes little difference to the results. Thus, the index used here is the Thirtle et al. (2004) index updated to 2005 using data from DEFRA. TFP grew at almost $2 \%$ per annum up until 1983. Then, for the 18 years from 1983 to 2005 , growth falls to $0.2 \%$. Indeed, the index is higher in 1983 than in 2000, although this is comparing a good year with a bad one. Then, there is some evidence of a slight recovery after 2000 .

The decline in TFP growth can be explained by public and private technology and returns to scale. Public sector R\&D has generated most of the biological technical change in the past, while mechanical technical change has been much more the province of the private sector, which has also much improved the chemical inputs, such as fertilizer, pesticide, and herbicide. The structure of UK public and private agricultural R\&D is explained in Thirtle et al. (1997). The TFP data are from 1953 to 2005. Public agricultural R\&D expenditures, in constant values, are updated from Thirtle et al. (1997). Although the series extend back to 1940, the long lags on R\&D prevent fitting to the full TFP sample; with a 27-year lag the model is still fitted to 40 years of data, from 1966. There is no R\&D expenditure data for the private sector, but from 1940 there are data on mechanical and chemical patents pertaining to agriculture, first used by Khatri and Thirtle (1996).

These are counts of all relevant patents registered in the USA, regardless of country of origin and where they were first used. These are the only patent series available that go back far enough, but they are quite suitable for capturing private activity in the UK, since Schimmelpfennig and Thirtle (1999) showed that international spillovers are more important than domestic patent activity for the European Union countries and also measured spillovers from foreign public research systems. The internationalization of private technology generation that has resulted from the increasing importance of multinational companies has led to a global pool of available technology and country of origin is relatively unimportant ${ }^{1}$. In addition to technical change, increasing returns to scale combined with increasing farm size may be expected to contribute to TFP growth and there are farm size data from 1953 onward from Thirtle et al. (2004). This article also investigates the evidence on how domestic and foreign patents and domestic public R\&D are related, but again the data begin only at 1973.

Thus, this study concentrates on the longest series available, in the hopes of not truncating the R\&D lag. The specification is less complete in other ways as a result and there may well be misspecification due to omitting variables that would capture other technology generating activities. However, the most obvious deficiency is the lack of extension data, which is further discussed later.

TFP growth appears to have followed the explanatory variables with a lag, as R\&D grew rapidly until 1981 and then declined, while both mechanical and chemical patent counts had ceased growing by the 1980s and farm size growth practically ceased a few years later. Thirtle et al. (2004) presents diagrams showing these series and the variables that are expected to be causally prior to TFP all turn before TFP stopped growing. This was the period when the Thatcher government severely reduced public expenditures on agricultural research. 
In a preliminary investigation of these relationships, the unrestricted model should include as many individual lagged values of the variables as are needed. If the relationship is assumed to be linear in logarithms, the ordinary least squares regression equation for substantiating the relationships explained above is $\operatorname{Ln} T F P_{t}=\beta_{0}+\beta_{1} \operatorname{LnR} \& D_{t-i}+\beta_{2} \operatorname{Ln} M P_{t-j}$

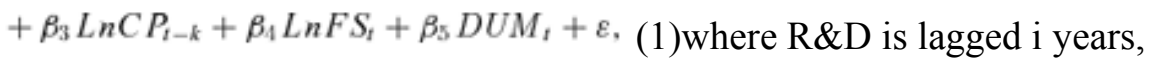

mechanical patents (MP) j years, and chemical patents (CP) k years. Farm size (FS) is not lagged and DUM is a dummy that is zero until 1983 and unity thereafter. The dummy variable is not crucial to the results, but can help to deal with the possible structural break at this point. This equation uses point estimates to find the lags that give the strongest impact on TFP and to drop those that are not significant. The strongest lag on R\&D was initially found to be 12 years, which can be viewed as the midpoint estimate of a 24-year lag structure. Thirtle et al. (2004) found a seconddegree polynomial 24 years long. Mechanical patents fitted best with the short lag of three years and chemical patents with no lag at all. The main objective of this exercise is to determine the strongest lags in order to guide the imposition of restrictions, which is what the distributed lags structures are.

The results are reported in Table 1, which makes it clear that lack of explanatory power is not the problem with these long series. The first columns, labeled Models 1 to 4 , show that R\&D alone explains $98 \%$ of the variance; farm size alone $94 \%$; mechanical patents alone $91 \%$; and chemical patents a more modest $39 \%$. When R\&D has this level of explanatory power (even without fitting it as a distributed lag) the problem is likely to be that the coefficients of the associated variables will not be significantly different from zero. In fact, Model 5 in Table 1 shows this is not the case either, as the elasticities of farm size, mechanical patents, and the structural break dummy are all significantly different from zero at the 5\% level. The test is taken to be one tailed as economic theory excludes negative elasticities. When chemical patents are added, as in Model 6, the significance levels are maintained, except in the case of farm size. 
Table 1

Explaining TFP change without lag structures, from 1953

\begin{tabular}{|c|c|c|c|c|c|c|c|c|}
\hline \multicolumn{9}{|c|}{ Dependent variable: Logarithm of TFP } \\
\hline Regressors & $\begin{array}{l}\text { Elasticity } \\
\text { (f-stat) } \\
\text { Model 1 }\end{array}$ & $\begin{array}{l}\text { Elasticity } \\
\text { (t)-stat) } \\
\text { Model } 2\end{array}$ & $\begin{array}{l}\text { Elasticity } \\
\text { (t } \text {-stat) } \\
\text { Model } 3\end{array}$ & $\begin{array}{l}\text { Elasticity } \\
\text { (f-stat) } \\
\text { Model } 4\end{array}$ & $\begin{array}{l}\text { Elasticity } \\
\text { (t-stat) } \\
\text { Model } 5\end{array}$ & $\begin{array}{l}\text { Elasticity } \\
(t \text {-stat) } \\
\text { Model } 6\end{array}$ & $\begin{array}{l}\text { Elasticity } \\
\text { (f-stat) } \\
\text { Model } 7\end{array}$ & $\begin{array}{l}\text { Elasticity } \\
\text { (t-stat) } \\
\text { Model } 8\end{array}$ \\
\hline Constant & $\begin{array}{c}4.4011 \\
(299.85)\end{array}$ & $\begin{array}{l}2.1670 \\
(19.47)\end{array}$ & $\begin{array}{r}3.570 \\
(54.83)\end{array}$ & $\begin{array}{l}8.3106 \\
(13.13)\end{array}$ & $\begin{array}{l}3.7884 \\
(24.05)\end{array}$ & $\begin{array}{c}3.5730 \\
(18.49)\end{array}$ & $\begin{array}{r}4.3046 \\
(29.822)\end{array}$ & $\begin{array}{l}4.3162 \\
(28.99)\end{array}$ \\
\hline Ln UKR\&D $l_{-10}$ & & & & & & & $\begin{array}{l}0.0758 \\
(2.33)\end{array}$ & $\begin{array}{l}0.0931 \\
(1.76)\end{array}$ \\
\hline L. UKR\&D UK-12 $_{l}$ & $\begin{array}{c}0.1412 \\
(42.37)\end{array}$ & & & & $\begin{array}{l}0.1233 \\
(6.77)\end{array}$ & $\begin{array}{l}0.1393 \\
(7.05)\end{array}$ & & \\
\hline Ln UKR\&D ${ }_{l-15}$ & & & & & & & & $\begin{array}{l}-0.0172 \\
(-0.42)\end{array}$ \\
\hline La UKR\&D ${ }_{t-24}$ & & & & & & & $\begin{array}{l}0.0291 \\
(1.83)\end{array}$ & $\begin{array}{l}0.0333 \\
(1.46)\end{array}$ \\
\hline Ln farm size & & $\begin{array}{c}0.6889 \\
(25.46)\end{array}$ & & & $\begin{array}{l}0.0996 \\
(1.86)\end{array}$ & $\begin{array}{l}0.0743 \\
(1.38)\end{array}$ & & \\
\hline $\begin{array}{l}\text { Ln mechanical } \\
\text { Patents } t_{-3}\end{array}$ & & & $\begin{array}{l}0.2712 \\
(21.58)\end{array}$ & & $\begin{array}{l}0.0392 \\
(2.04)\end{array}$ & $\begin{array}{l}0.0327 \\
(1.72)\end{array}$ & $\begin{array}{l}0.0524 \\
(1.81)\end{array}$ & $\begin{array}{l}0.0462 \\
(1.41)\end{array}$ \\
\hline Ln chemical & & & & -0.5590 & & 0.0463 & & \\
\hline Structural break & & & & & 0.0191 & 0.0212 & & \\
\hline Dummy & & & & & $(1.76)$ & $(1.99)$ & & \\
\hline Adjusted $R^{2}$ & 0.9792 & 0.9391 & 0.9117 & 0.3931 & 0.9826 & 0.9835 & 0.9323 & 0.9304 \\
\hline Durbin Watson & 1.220 & 0.411 & 1.342 & 0.570 & 1.406 & 1.3325 & 1.493 & 1.464 \\
\hline Akaike (AIC) & -105.461 & -79.465 & -69.063 & -24.469 & -107.156 & -109.059 & -78.402 & -78.102 \\
\hline Schwarz (SBIC) & -103.59 & -77.77 & -67.19 & -22.60 & -102.48 & -103.445 & -75.186 & -74.074 \\
\hline Log likelihood & 107.114 & 81.64 & 70.053 & 24.272 & 112.156 & 115.059 & 82.402 & 83.102 \\
\hline
\end{tabular}

Model 7 simply shows that the elasticity of R\&D is significant with lags of both 10 and 24 years, which may suggest a bimodal lag distribution, especially as Model 8 shows that the coefficient is negative and insignificant at 15 years. Note too that if only R\&D is used to explain TFP, the elasticity is biased upward. With over $98 \%$ of the variance already explained the coefficient on the weather index was not significantly different from zero. Lastly, the Durbin Watson statistics for these more completely specified regressions (Models 5 to 8) are in the indeterminate range, so serial correlation is not pursued further at this point.

Whatever criteria are used for model selection, it is clear that Model 5 is likely to be preferred as it has the joint highest adjusted $\mathrm{R}^{2}$ and the best Akaike Information Criteria (AIC) and Likelihood statistics. The Schwarz Bayes Information Criteria (SBIC) statistic is almost top as well and it is only let down by the Durbin Watson statistic. As this can be taken to indicate misspecification, Models 7 and 8 , which have more than one lag of $R \& D$, would be preferred in this respect, but fare far less well in all the other tests. This issue of multiple impacts of R\&D will be further investigated later, but note that although the more completely specified models have good test statistics, the improvement over Model 1 is very limited. One 12-period lag of R\&D comes close to being the preferred model.

These powerful results can be compared with the tenuous outcomes reported by Thirtle and Bottomley (1989), when the series were far shorter and the TFP index less competently measured. Though that study analyzed all five different TFP indices that were then available, the highest adjusted $\mathrm{R}^{2}$ obtained was only 0.75 . Whilst this improvement is encouraging, the long time series now available also means that these data can now be subjected to more rigorous examination using time series techniques. The relationships postulated above may prove to be spurious according to the improved standards set by improvements in time series econometrics. Then there is the issue of using the information gained above in adequately modeling the R\&D, mechanical and chemical patents, as all three are capital stocks, which need lag 
distributions to be imposed or estimated. This is not likely to improve regressions in which as much as $98 \%$ of the variance is already explained and the point estimates of the elasticities usually prove to be good approximations of the elasticities obtained using stock variables. However, if either the length or shape of the lag structure is incorrect, the elasticity estimates will be both inefficient and biased because of omitted variables. Also, both length and shape matter in that they affect the ROR considerably, since future impacts are discounted and information on the distribution of these impacts is important

\section{Time series tests, cointegration, and causality}

The time series properties of the variables are now checked using the augmented Dickey Fuller (ADF) tests reported in Table 2, which shows that all the variables used in Eq. (1) are stationary in first differences, so the equation may have a cointegrating regression.

Table 2

Time series characteristics and order of integration of the variables

\begin{tabular}{lccll}
\hline Variable & $\begin{array}{c}\text { ADF test } \\
\text { (critical value) }\end{array}$ & $\begin{array}{c}\text { Trend/ } \\
\text { intercept }\end{array}$ & Characteristics & $\begin{array}{l}\text { AR } \\
\text { order }\end{array}$ \\
\hline TFP & $-1.88(-2.93)$ & Intercept & & 1 \\
$\Delta$ TFP & $-8.44(2.92)$ & Both & I(1) & 1 \\
UKR\&D & $-2.49(-3.50)$ & Both & & 1 \\
$\Delta$ UKR\&D & $-6.73(-3.50)$ & Both & I(1) & 1 \\
Chemical patents & $-2.71(-2.92)$ & Intercept & & 1 \\
$\Delta$ Chemical patents & $-5.55(-1.95)$ & None & I(1) & 2 \\
Mechanical patents & $-1.83(-2.92)$ & Intercept & & 5 \\
$\Delta$ Mechanical pats & $-4.26(-2.92)$ & Intercept & I(1) & 4 \\
Farm size & $-2.73(-2.92)$ & Intercept & & 1 \\
$\Delta$ Farm size & $-5.90(-3.50)$ & Both & I(1) & 1 \\
\hline
\end{tabular}

For this to be so, a linear combination of the variables must exist that is integrated an order one less than the original variables. That is, the error term from the cointegrating regression must be stationary. Since the coefficients estimated in Table 1 are an efficient and unbiased linear combination of the variables, it is reasonable to check that equation for cointegration. The ADF test, with no intercept or trend, reported in Table 3 has the null hypothesis of a unit root, which is rejected at the 5\% level, meaning that the residuals are stationary and this is a cointegrating regression (Vogelvang, 2005). The more general maximum likelihood approach of Johansen (1988) allows estimation of all cointegrating relationships and tests for the number of cointegrating vectors and the direction of causality. The null hypothesis of no cointegrating vectors is rejected in both the Eigenvalue and Trace tests, but that of less than two cointegrating vectors is not rejected. This implies that there is one cointegrating vector and there should be Granger causality in one direction, so the next test is to establish this. 


\section{Table 3}

Johansen cointegration results

\begin{tabular}{|c|c|c|}
\hline $\mathrm{ADF}$ & Eigenvalue test & Trace test \\
\hline$-2.6212(-1.9489)$ & $4.5285(3.8415)$ & 4.5285 (3.8415) \\
\hline
\end{tabular}

The $\chi^{2}$ statistics in the first row of Table 4 test to see if R\&D, patents, and farm size are Granger-prior to TFP and the probabilities in the next row show that this is true for all the explanatory variables, which is the required result. The remainder of the table shows that there is little evidence of any feedbacks in the opposite direction, although TFP and farm size do appear to be causally prior to chemical patents, which are themselves prior to mechanical patents.

\section{Table 4}

Granger causality Wald tests-Vector autoregressions

\begin{tabular}{|c|c|c|c|c|c|c|}
\hline Equation & TFP & UKR\&D & Farm size & Chemical patents & Mechanical patents & All \\
\hline \multicolumn{7}{|c|}{ TFP (dependent variable) } \\
\hline$x^{2}$ & & 27.29 & 6.3673 & 4.8007 & 7.3354 & 46.211 \\
\hline Prob $>x^{2}$ & & 0.000 & 0.041 & 0.091 & 0.026 & 0.000 \\
\hline \multicolumn{7}{|c|}{ UKR\&D (dependent variable) } \\
\hline$x^{2}$ & 0.17217 & & 2.2471 & 0.05173 & 2.7552 & 6.2479 \\
\hline Prob $>x^{2}$ & 0.918 & & 0.325 & 0.974 & 0.252 & 0.715 \\
\hline \multicolumn{7}{|c|}{ Farm size (dependent variable) } \\
\hline$x^{2}$ & 0.91686 & 0.62934 & & 1.3573 & 1.6997 & 11.686 \\
\hline Prob $>x^{2}$ & 0.632 & 0.730 & & 0.507 & 0.427 & 0.232 \\
\hline \multicolumn{7}{|c|}{ Chemical patents (dependent variable) } \\
\hline$x^{2}$ & 5.4891 & 1.0247 & 7.7287 & & 1.0357 & 30.725 \\
\hline Prob $>x^{2}$ & 0.064 & 0.599 & 0.021 & & 0.596 & 0.000 \\
\hline \multicolumn{7}{|c|}{ Mechanical patents (dependent variable) } \\
\hline$x^{2}$ & 0.15252 & 2.3391 & 3.4857 & 5.1075 & & 20.741 \\
\hline \multirow[t]{5}{*}{ Prob $>x^{2}$} & 0.927 & 0.311 & 0.175 & 0.078 & & 0.014 \\
\hline & Log likelihood & & & & 1608.525 & \\
\hline & AIC & & & & -69.84204 & \\
\hline & SBIC & & & & -66.92246 & \\
\hline & HQIC & & & & -68.75932 & \\
\hline
\end{tabular}

Having established cointegration and causality in the required direction it may be possible to represent the relationships as an error correction model (ECM) as Granger's representation theorem proves that a cointegrated system of variables can be adequately represented as an ECM (Engle and Granger, 1987). The ECM form did not prove to be suitable for modeling the long lags inherent in technology generation, so the more conventional path of fitting distributed lag structures or creating stock variables is followed here. However, the properties of the data continue to be the center of attention, as models of the lag structures provide some continuity with the time series approach used so far (see Gilbert, 1990). 


\section{Modeling lag length and shape}

\subsection{Lag relationships between research and productivity growth}

Expenditures on R\&D are investments generating new technologies that augment the existing stock of techniques, which are at the same time being diminished by depreciation as old technologies cease to affect productivity. All attempts at modeling capital stocks amount to estimating or imposing the weights on a lag distribution (quite simply a weighted moving average). There are numerous alternative shapes, many of which are well summarized in Maddala (1977, Ch.16), but in most cases the impact of new investment must be determined and so must the rate of depreciation. However, when the lag covers the entire relationship from R\&D expenditures to the impact on farm level TFP, rather more is involved. First, there is the lag from expenditures to technology generation, followed by the diffusion lag.

For patents, the gestation lag is removed, but the rates of diffusion and depreciation have to be captured. One extreme is the lack of diffusion lag and exponential decay of patent knowledge stocks that were pre-constructed by Khatri and Thirtle (1996), using a perpetual inventory model (PIM), where the patent's stock in year $t$ is the number of patents registered in year t plus the stock of past patents, multiplied by $(1-\delta)$, where $\delta$ is the depreciation rate and is set at 0.08 . The significance of 0.08 is that a patent's contribution becomes negligible after 17 years, which was roughly the life of a U.S. utility patent during this period. Other common alternatives are the linear distributed lag (akin to straight line depreciation), the uniform distribution of a simple moving average, inverted $\mathrm{V}$ or trapezoidal shapes, and inverted $\mathrm{U}$ shapes associated with Almon lags. The last three of these allow for both gradual adoption and decay.

Thus, Alston et al. (2000) found that in agricultural economics the two most common approaches have been low-order polynomial lags and pre-constructed trapezoid and inverted V lags. In the second-degree PDL structures, usually both end points are constrained to equal zero and the R\&D is in logarithms. The inverted U shape, formed by the estimated elasticity weights of the PDL, is thus the shape of the knowledge capital stock. Alternatively, a knowledge stock variable can be manually created and imposed, using inverted $\mathrm{V}$ or trapezoidal lag weights, to give an alternative form of moving average, which is then subjected to logarithmic transformation.

Thus, the two approaches are somewhat different in that the trapezoid is used to construct a knowledge stock and then the logarithm is taken, whereas the PDL is estimated with the R\&D data in logarithms. The PDL was intended to allow estimation of elasticities for individual years, while still conserving degrees of freedom and overcoming the fact that unconstrained estimation is difficult because numerous lags of the same variable are normally collinear. The PDL and trapezoid are compared in Fig. 2, using UK data. The diamonds in the figure depict a second-degree PDL, which allows only one turning point and is also constrained to zero at each end point. Test statistics like those reported in Table 1 were used to select the preferred model, which was found to have a three-year lead time, meaning that the lag begins at zero in the third year and then persists for 25 years. 


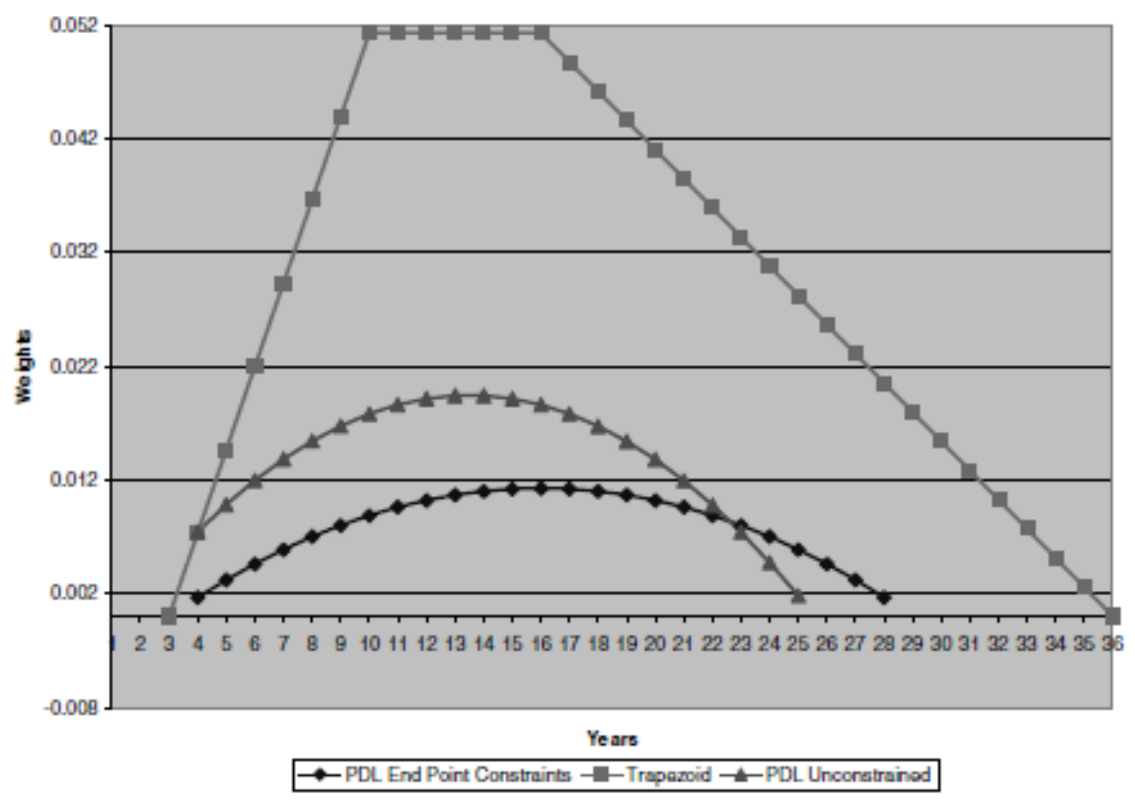

Fig. 2. Constrained polynomial, trapezoid, and unconstrained PDLs.

The estimated coefficients for the PDL, which are elasticities, since all the variables are in logarithms, are reported in the first column of Table 5 (Model 9), while the tstatistic of 6.30 in the second column shows that they are collectively statistically different from zero. The other technology variables are mechanical and chemical patents pertaining to agriculture, for which several alternatives were tried for creating stocks. The PIM and other pre-constructed series did not give significant estimates, but when chemical patents are modeled as a stock using a five period, second-degree PDL, again constrained to equal zero at both end points, the PDL is significant and model fit is improved. Mechanical patents are modeled in the same way, but with a one-year lead time and seven period lag. Together the private sector patent series have elasticities that sum to almost 0.3 , which is greater impact than the total R\&D elasticity of 0.2 . This reflects the fact that private sector expenditures in the advanced countries have overtaken public expenditures (Alston et al., 1999). Farm size is also included, to capture the possible contribution of increasing returns to scale in TFP growth, as farm size was growing substantially until the late 1980s, when it stabilized and then fell. The farm size variable was not significant, but the diminishing and then declining growth is captured by the negative sign on farm size squared, which was included to deal with this nonlinearity. 
Table 5

Results for constrained PDL, trapezoidal, and beta lag distributions

\begin{tabular}{|c|c|c|c|c|c|c|}
\hline \multirow[t]{2}{*}{ Vatatle } & \multicolumn{2}{|c|}{ WDL contrainat (Modd 9) } & \multicolumn{2}{|c|}{ Traperold (Modd DO) } & \multicolumn{2}{|c|}{ Fl. encreitrainad (Modd 11) } \\
\hline & Crefliciant & frat & Coeflician: & f-wat & Coeflicion: & tulat \\
\hline Conubart & 14800 & 9.68 & 30415 & 9.2 & 1.04621 & 6.38572 \\
\hline LCanse & a.0172 & 243 & Das234 & 2.61 & 0.02435 & 254138 \\
\hline LantaMer(-1) & 0.0074 & 243 & Dosm & 2.61 & 0.03m2s & 254138 \\
\hline LCamMEN-2) & a.coson & 243 & 0.0434 & 2.61 & 0.044313 & 254138 \\
\hline Lantwas(-3) & 0.0024 & 243 & 0.43 & 2.61 & $0.03 m 2 s$ & 254138 \\
\hline 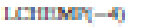 & 0.0172 & 2.43 & 00234 & 2.61 & 0.024345 & 2.54138 \\
\hline aEmpstocx & 0.1201 & & $0.12 n 21$ & & 0.17465 & \\
\hline LWRMEsTri" & $-0 \operatorname{cosex}$ & -3.51 & -00529 & -2.52 & -0.06615 & -3.21400 \\
\hline LeNon & & & Dotse & 1.12 & & \\
\hline Luarar-1) & & & Doses & 1.12 & & \\
\hline LMNOIT-1) & 0.0142 & M.es & adans & 3.12 & 0.01736s & $1.5008 s$ \\
\hline LMACIIY -3$)$ & 0.0043 & 3.es & דיטם & 3.12 & 0.022273 & 1.30038 \\
\hline LeNomy-4) & a.0sos & 3.es & oons & 3.12 & 0.02s & 1.50038 \\
\hline LMACIIY-9) & 0.0024 & 3.65 & Doses & 3.12 & $0.035 \pi$ & 1.50038 \\
\hline LeNoury -6 & 0.0004 & 3.es & Dotse & 3.12 & 0.022275 & 1.scosss \\
\hline LNATI & 0.0043 & 3.68 & & & 0.01736s & 1.scosss \\
\hline LeNom-15 & 0.0142 & 3.es & & & & \\
\hline I MACITLACIS & 0.1701 & & 0.1554 & & 0.12434 & \\
\hline \multirow{2}{*}{\multicolumn{7}{|c|}{ 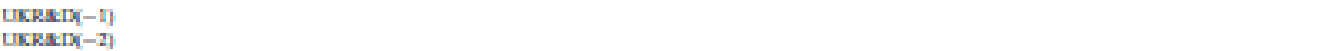 }} \\
\hline & & & & & & \\
\hline 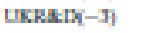 & 0.0017 & $\cos 2$ & & & 0.0004 & Deseares \\
\hline UKEs: $(-4)$ & 0.00032 & 6.52 & & & 0.0005 & 1.08087 \\
\hline UKEs: $(-5)$ & 0.0046 & $\cos 52$ & & & 0.0130 & 1.45400 \\
\hline UKE:DD $(-6)$ & $\operatorname{accs} \theta$ & $\cos 22$ & & & 0.013s & 1.55228 \\
\hline UKESDA-T & 0.007 & 6.52 & & & 0.0154 & 2.15017 \\
\hline uxks: $(-1)$ & 0.006 & $\cos 25$ & & & 0.058 & 2.28218 \\
\hline UKR:DX $(-3)$ & 0.000 & 6.52 & & & 0.0173 & $2.28+71$ \\
\hline UKE:DS(-10) & 0.0006 & 652 & & & o.ots & 2.21545 \\
\hline UKEs:D(-11) & 0.0102 & 6.52 & & & 6.0ะ3n & 2.16774 \\
\hline UK:k:DX $(-12)$ & 0.0107 & 6.52 & & & 0.0134 & 2.1284 \\
\hline UKE:DX(-13) & 0.011 & 2.52 & & & 0.0134 & 200036 \\
\hline UKR:DX $(-14)$ & 0.0112 & 6.32 & & & o.013n & $20 \mathrm{kng}$ \\
\hline UKE:DX(-15) & 0.0113 & 62 & & & o.0ts & 205ent \\
\hline UKE:DD $(-16)$ & 0.0112 & 62 & & & 0.017 & 2.13421 \\
\hline UKR:DX $(-17)$ & 0.011 & $\cos 2$ & & & 0.058 & $2.2 n e s 7$ \\
\hline UKEs:X(-15) & 0.0107 & 6.52 & & & 0.0154 & 23150 \\
\hline UKE:DX $(-1 \%)$ & 0.0102 & $\cos 2$ & & & 0.013 & 2.50204 \\
\hline UKR:DX $(-30)$ & 0.0006 & 6.52 & & & 0.012 & 3000372 \\
\hline UKE:DX(-21) & 0.000 & 6.52 & & & 0.0005 & 3.3ens \\
\hline UKRax $(-22)$ & a.cos & 6.50 & & & 0.0004 & $4.72 a c s$ \\
\hline UKENDX(-2T) & 0.007 & 6.52 & & & 0.004 & $1 . \operatorname{ses} 2$ \\
\hline UKE:DDX $(-24)$ & 0.0089 & 62 & & & $0.000 \mathrm{~s}$ & 0.351911 \\
\hline $\operatorname{Urks} \times x(-25)$ & 0.0046 & 62 & & & -0.0004 & $-0.17 \operatorname{mes}$ \\
\hline UKENDX(-25) & 0.0002 & 6.52 & & & -0.0043 & $-0.48000 \%$ \\
\hline UKRSD(-27) & 0.0017 & 6.52 & & & -0.00s & $-0,111 \% 5$ \\
\hline R.E.D adod & 0.1581 & & a.m & (35 Lapis 6.51 & 0.258 & \\
\hline Dutian Wabsoa & $1 . \pi \operatorname{ses}$ & & $1.4 \mathrm{gr}$ & & $1 . x a n$ & \\
\hline max: & -72.61 & & $-\pi m$ & & -75.2300 & \\
\hline $\operatorname{san} \mathrm{R}^{2}$ & asas & & o.3n & & 0.9280 & \\
\hline Log Hedibood & an:Tis & & 10.768 & & $5 \times 590$ & \\
\hline
\end{tabular}

Note: *The number of estimated parameters for the PDLs is the degree of the polynomial, plus one.

The square symbols in Fig. 2 depict the shape of the trapezoidal lag used to construct the R\&D knowledge stock in the alternative approach. The greater size should be ignored as the coefficients reflect the weights used rather than estimated elasticities. The lag of 35 years and the weights are the same as Huffman and Evenson (2006, p. 671) have used for the USA and Mullen and Cox (1995) for Australian broadacre agriculture. To keep the results comparable to the PDL, it is fitted from 1967 to 2003, although this does mean projecting the 1940 value for R\&D back another 10 years. ${ }^{2}$ The program estimates a single elasticity, of 0.172 , for this logarithmic knowledge stock variable, rather than annual coefficients. In comparison with the PDL, the R\&D elasticity is lower and those for both patent series are higher. All the test statistics for Model 10 (the Durbin Watson, the SBIC, the log likelihood, and adjusted $\mathrm{R}^{2}$ ) are 
inferior, which suggests that even with a restrictive lag shape like the second-order PDL, letting the data choose the lag weights may be preferable to imposing them ex ante. Note though, that in terms of all the test statistics except the Durbin Watson, neither of these commonly used models fares as well as Model 1, let alone the better models in Table 1, such as Model 5. Attempting to allow for the lag distribution seems to impose penalties rather than improving the results, partly because the lag distribution cuts 10 years from the period for which the model can be fitted.

Neither of the models fitted so far allows very much scope for the data to determine the shape of the lag distribution, so the first step in this direction is an unconstrained (neither end point set equal to zero) second-degree PDL. Frequently the lack of constraints results in unfortunate results, such as the PDL inverting itself, but these UK data now seem to be sufficient to support unconstrained estimates. The lag remains an inverted $\mathrm{U}$, as the triangles in Fig. 2 show, but is no longer entirely symmetric. There is further useful information in Model 11, as the last column of Table 5 reports t-statistics for each year individually. These last results show that only the lags from five to 23 years are significantly different from zero. Even so, the sum of the significant lagged elasticities is 0.29 , which is considerably greater than in the less flexible models. The two patent series are again estimated as PDLs, but relative to Model 9 that also has patent PDLs, the emphasis indicated by the two elasticities is reversed, with chemical patents now having the larger impact. In terms of model selection criteria, there is very little difference from the constrained model, which does indicate that end point constraints are valid.

None of the models fitted so far allows much scope for the data to determine the shape of the lag distribution, so the remaining models try to impose fewer priors. Extensive use is made of model selection criteria, to allow the data to determine (i) the appropriate lag specification, (ii) the shape of the lag distribution, (iii) the lag length, and (iv) the lead time (the number of initial zero lag coefficients). There are a large number of finite and infinite lag distributions to choose from, reviewed in Maddala (1977, Ch. 16) and Judge et al. (1985, Chs. 9 and 10). A discussion of the methods used for the data-determined lag shapes and lengths can be found in Khatri and Thirtle (2000). The first two flexible structures considered are the gamma and beta distributed lags, which are explained below.

\subsection{Gamma and beta distributed lags}

These lag distributions assume that the lag coefficients lie on multiples of gamma and beta density functions. The gamma distribution is a flexible unimodal distribution that can approximate many of the forms mentioned above and allows for a skewed distribution. Particularly, Huffman and Evenson $(1989,1992)$ experimented extensively with lag shapes and favor a trapezoidal form for the R\&D knowledge stock, as in Model 10 above. It increases linearly for seven years, is constant for six years, and declines for 20 years. The gamma distribution is of interest since it offers a smooth form of such a trapezoid, which can be estimated rather than imposed. It assumes that the lag coefficients lie on a multiple of the gamma density function. Judge et al. (1985) present Tsurumi's (1971) truncated form of the distribution, Schmidt's (1974) more flexible two-parameter distribution, and some simplifications. The empirical form of the gamma distribution that combines amendments from Tsurumi and Schmidt is $\beta_{i}=\alpha(i+1)^{s-1} e^{-Y_{i}}, i=0,1, \ldots,(2)$ where $\alpha$ and $\mathrm{S}$ are 
parameters to be estimated. Judge et al. (1985, Fig. 10.1) notes that the lag can take many shapes, according to the value of S.

$$
\begin{aligned}
& y_{t}=\alpha Z_{t}+\eta_{t}+e_{t} \\
& Z_{t}=\sum_{i=0}^{t-1} \frac{\beta_{i}}{\alpha} x_{t-i} \\
& \eta_{t}=\sum_{i=t}^{\text {infinity }} \beta_{i} x_{t-i} .
\end{aligned}
$$

For estimation, the function can be written as

(3)Schmidt suggests the last expression in Eq. (3) can be regarded as the truncated remainder, which although time-dependent, is asymptotically negligible and thus can be omitted in estimation. The parameters $S, \gamma$, and $\alpha$ can be estimated from (3) to provide the approximating empirical form of the general gamma distribution. The gamma distribution provides a flexible structure suited to positively skewed distributions and ensures positive coefficients and a unique mode, for $\mathrm{s}>1$.

Equation (3) was estimated with and without the other exogenous variables, using a grid search over a considerable range of starting values in an attempt to derive maximum likelihood estimates. The lack of convergence of the estimation algorithms was taken to indicate the inappropriateness of the gamma distribution. This suggests that the appropriate distribution has a negative skew, rather than the positive skew of the gamma distribution and the trapezoid of Model 10. This complies with previous results for both the UK and the USA. For the UK, Khatri (1994) found that the best fit was the beta lag distribution (chosen according to Pearson's method of moments) with a pronounced negative skew and 18 years of lags. Chavas and Cox (1992) found a considerably negatively skewed distribution (corresponding to a beta type distribution) for the U.S. public sector (more basic) agricultural research whereas the lag for private sector (applied/developmental) research was shorter and positively skewed, similar to the gamma distribution. For South Africa, which has an effective R\&D system that concentrates on adaptive research, Khatri and Thirtle (2000) found a short lag of up to nine years, with a strong positive skew, which was best modeled with the gamma (or generalized exponential) distribution.

The beta distribution lag coefficients are defined as $\beta_{i}=\alpha(i)^{p-1}(1-i)^{q-1}$, (4)where $\beta_{\mathrm{i}}$ is the ith lag coefficient and $\alpha, p$, and q (together with the coefficients of the other conditioning factors) are estimated using maximum likelihood techniques. The beta distribution again ensures positive coefficients with a unique mode and is also a flexible structure that is suited to negatively skewed distributions. The nonlinear estimation algorithm converged reassuringly quickly to a solution for the beta distribution, with or without the patent and farm size variables.

The diamonds in Fig. 3 depict the case where the other exogenous variables are omitted and the results show the distinctive negative skew that typifies the beta distribution. This model is not reported in the Table, as it is clearly misspecified, but correcting the specification by including the omitted variables changes the result entirely, as the second lag shape, depicted by squares, shows. This lag is not negatively skewed and is most like the PDL, but with positive and negative tails, rather like the normal distribution. Thus, if up to three turning points must be allowed for, the best choice of lag shape would be a fourth-degree polynomial. This shows both the flexibility of the beta distribution and the interdependence of the public and 
private technology generating activities. The R\&D lag cannot be assumed to be independent of patents and farm size and should not be estimated alone.

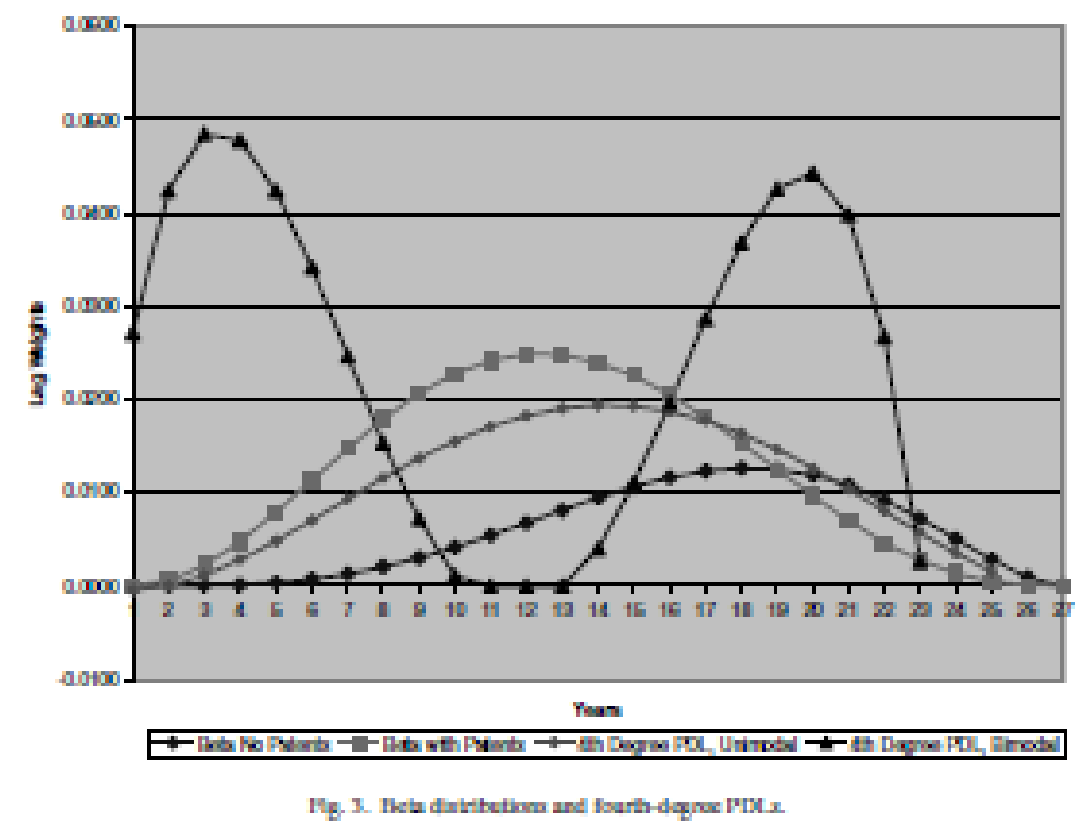

Fig. 3. Beta distributions and fourth-degree PDLs.

If the shorter-run patent variables are omitted, the expectation would be that the public R\&D variable would pick up their effects on TFP and would have higher coefficients for the early years. Comparing the two beta lags in Fig. 3 shows that the opposite is true here, with the elasticities for the early years of the R\&D lag increasing substantially when patents are included and the later years diminishing. Perhaps this indicates that public R\&D and patents are complements, which was suggested by Thirtle et al. (2004). Compared with the PDLs and the trapezoid of Table 5, Table 6 shows the flexibility of the beta lag results (Model 12) and a total R\&D elasticity of 0.32 , which is even higher than the unconstrained PDL. The impact of the mechanical patent series is not much changed, but chemical patents now have an elasticity of only 0.034 . This may be due to the better fit of the more flexible beta lag, which precluded the use of PDLs for the patent variables. Instead, the chemical patent's stock was included as a four year moving average and the mechanical patents as a moving average of the lags at six and seven years. 
Table 6

Beta and fourth-degree PDL distributions

\begin{tabular}{|c|c|c|c|c|c|c|}
\hline \multirow[t]{2}{*}{ Variable } & \multicolumn{2}{|c|}{ Beta (Model 12) } & \multicolumn{2}{|c|}{ PDL, Bimodal (Model 13) } & \multicolumn{2}{|c|}{ PDL, Unimodal (Model 14) } \\
\hline & Coefficient & $t$-stat & Coefficient & $t$-stat & Coefficient & $t$-stat \\
\hline Constant & 3.3491 & 7.77 & 3.29346 & 9.29738 & 2.72218 & 4.74069 \\
\hline LCHEMP & & & 0.10676 & 2.95182 & 0.023252 & 2.71453 \\
\hline LCHEMP(-1) & & & & & 0.038753 & 2.71453 \\
\hline LCHEMP( -2$)$ & & & & & 0.046503 & 2.71453 \\
\hline LCHEMP(-3) & & & & & 0.046503 & 2.71453 \\
\hline LCHEMP $(-4)$ & & & & & 0.038753 & 2.71453 \\
\hline LCHEMP $(-5)$ & & & & & 0.023252 & 2.71453 \\
\hline CHEMP STOCK & 0.0339 & 2.14 & & & 0.217016 & \\
\hline LFARMSIZEE & -0.0601 & -2.55 & -0.097 & -3.76247 & -0.06376 & -3.24003 \\
\hline \multirow{2}{*}{\multicolumn{7}{|c|}{ LMACHP }} \\
\hline & & & & & & \\
\hline LMACHP(-2) & & & 0.010739 & 1.60419 & 0.016696 & 2.71414 \\
\hline LMACHP(-3) & & & 0.018409 & 1.60419 & 0.027827 & 2.71414 \\
\hline LMACHP(-4) & & & 0.023012 & 1.60419 & 0.033392 & 2.71414 \\
\hline LMACHP(-5) & & & 0.024546 & 1.60419 & 0.033392 & 2.71414 \\
\hline LMACHP(-6) & 0.0499 & 1.53 & 0.023012 & 1.60419 & 0.027827 & 2.71414 \\
\hline LMACHP(-7) & & & 0.018409 & 1.60419 & 0.016696 & 2.71414 \\
\hline LMACHP(-8) & & & 0.010739 & 1.60419 & & \\
\hline$\Sigma$ MACHP LAGS & 0.138 & 1.84 & 0.128866 & & 0.15583 & \\
\hline UKR\&D(-1) & 0.0005 & 0.16 & & & -0.0004 & -0.07186 \\
\hline UKR\&D(-2) & 0.0022 & 0.26 & & & 0.0000 & $3.35 E-04$ \\
\hline UKR\&D( $(-3)$ & 0.0047 & 0.38 & 0.027119 & 2.52658 & 0.0011 & 0.104939 \\
\hline UKR\&D $(-4)$ & 0.0079 & 0.56 & 0.0424 & 2.57698 & 0.0028 & 0.26427 \\
\hline UKR\&D $(-5)$ & 0.0113 & 0.83 & 0.048488 & 2.64235 & 0.0048 & 0.521215 \\
\hline UKR\&D(-6) & 0.0147 & 1.29 & 0.047767 & 2.72642 & 0.0070 & 0.951827 \\
\hline UKR\&D(-7) & 0.0179 & 2.05 & 0.042359 & 2.82557 & 0.0093 & 1.59428 \\
\hline UKR\&D(-8) & 0.0206 & 2.83 & 0.034128 & 2.89248 & 0.0116 & 2.06268 \\
\hline UKR\&D(-9) & 0.0227 & 2.77 & 0.024673 & 2.70254 & 0.0137 & 2.00422 \\
\hline UKR\&D $(-10)$ & 0.0242 & 2.34 & 0.015337 & 1.86347 & 0.0155 & 1.8087 \\
\hline UKR\&D $(-11)$ & 0.0248 & 2.07 & $7.20 E-03$ & 0.785427 & 0.0171 & 1.67328 \\
\hline UKR\&D $(-12)$ & 0.0248 & 1.95 & $1.07 E-03$ & 0.1009 & 0.0183 & 1.61067 \\
\hline UKR\&D(-13) & 0.024 & 1.97 & $-2.48 E-03$ & -0.21266 & 0.0190 & 1.61174 \\
\hline UKR\&D(-14) & 0.0225 & 2.14 & $-3.16 E-03$ & -0.26771 & 0.0194 & 1.67688 \\
\hline UKR\&D(-15) & 0.0205 & 2.57 & $-9.29 E-04$ & -0.08391 & 0.0193 & 1.82353 \\
\hline UKR\&D $(-16)$ & 0.0181 & 3.55 & $3.98 E-03$ & 0.402221 & 0.0187 & 2. 10172 \\
\hline UKR\&D $(-17)$ & 0.0153 & 5.06 & 0.011084 & 1.21404 & 0.0177 & 2.64854 \\
\hline UKR\&D $(-18)$ & 0.0125 & 3.34 & 0.019638 & 1.99028 & 0.0163 & 3.90934 \\
\hline UKR\&D $(-19)$ & 0.0096 & 1.75 & 0.028633 & 2.35193 & 0.0146 & 6.70904 \\
\hline UKR\&D(-20) & 0.007 & 1.05 & 0.036802 & 2.44715 & 0.0126 & 4.0698 \\
\hline UKR\&D(-21) & 0.0047 & 0.68 & 0.042616 & 2.45925 & 0.0104 & 1.93781 \\
\hline UKR\&D(-22) & 0.0027 & 0.47 & 0.044283 & 2.45505 & 0.0081 & 1.11433 \\
\hline UKR\&D(-23) & 0.0013 & 0.33 & 0.039753 & 2.4449 & 0.0057 & 0.704597 \\
\hline UKR\&D $(-24)$ & 0.0005 & 0.27 & 0.026714 & 2.31249 & 0.0035 & 0.464274 \\
\hline UKR\&D(-25) & 0.0001 & 0.15 & 0.000259 & 0.29632 & 0.0016 & 0.308081 \\
\hline UKR\&D $(-26)$ & & & -0.03544 & -1.61889 & & \\
\hline UKR\&D(-27) & & & -0.09049 & -1.96072 & & \\
\hline R\&D stock & 0.3153 & & 0.52071 & & 0.2334787 & \\
\hline Durbin Watson & 1.5386 & & 1.71767 & & 1.638 & \\
\hline BSIC & -79.999 & & -74.91 & & -85.244 & \\
\hline ADJ $R^{2}$ & 0.9327 & & 0.9311 & & 0.94799 & \\
\hline Log likelihood & 92.987 & & 89.3548 & & 98.3263 & \\
\hline
\end{tabular}

The model selection criteria suggest that this is the best model so far, as the test statistics improve and so does the adjusted $\mathrm{R}^{2}$, although the Durbin Watson statistic suggests a possible problem with serial correlation. The second column of Table 5 shows that only the lags from six to 19 years are significantly different from zero. Perhaps more interesting is the fact that the more flexible beta distribution is still unimodal. A final concern is that Models 7 and 8 in Table 1 suggested the possibility of a bimodal R\&D lag by showing significant R\&D lags of 10 and 24 years. Although the beta and gamma lags allow for skewness, all the models tested thus far impose lag structures that are unimodal and that may be finding maximum elasticities in the midrange of the lag structure because they average the impacts from a distribution that is actually bimodal.

Thus, the final models estimated here are the least restrictive. Model 13 in Table 6 is a fourth-degree polynomial, with the starting value constrained, but not the end point. 
The improvement in the UK data is clear here, as models with this many degrees of freedom never worked with old data prior to DEFRA's new TFP series. The triangles in Fig. 3 show a very pronounced bimodal distribution with peaks at three and 20 years. This would indicate that it might be possible to separate out the effects of shortrun $R \& D$ activities from the impact of projects with a long gestation period. Similar results have been reported for the USA by Chavas and Cox (1992) using a nonparametric model, and by Oehmke and Schimmelpfennig (2004), who found impacts of public R\&D at 2 years and 24 years using impulse response functions. Table 6 shows that the elasticities are significantly different from zero for the years from 1 to 10 and from 18 to 24, with insignificant values in between. Thus, the seven years from lags 11 to 17 are all insignificant, and these are the lags that have the highest elasticities in all the previous models. The sum of the elasticities increases to 0.52, while the impacts of the patents series are maintained, despite the lack of lagged values for chemical patents. This weakness, combined with model selection criteria that show this model finishes (a close) second to the beta lag, leads to further estimation. However, the most telling result may be the Durbin Watson statistic, which is now in the acceptable zone rather than being in the indeterminate area. This might be taken to indicate that the bimodal specification is sufficiently correct to avoid serial correlation problems.

The final model, represented by the circles in Fig. 3, is remarkably similar to the beta distribution and a normal curve. This results from modeling both patent stocks as PDLs, which seems to restore the parity between the two private R\&D series' that was emerging earlier. The bimodal form has now, however, gone as the last column of Table 6 shows. The lags from 7 to 21 are significant and show a distinctly unimodal lag shape. This model has model selection criteria that are clearly superior, explains $95 \%$ of the variance, and has all three technology series properly modeled as stocks. The private sector elasticities sum to 0.38 and the public R\&D still has a substantial elasticity of 0.23 . This overall "best" model is unimodal, but there remains some possibility that if private sector impacts on productivity could be measured more finely, that the bimodal distribution of public R\&D impacts might emerge again. Throughout this discussion, the effect of omitting relevant technology variables has been shown to be serious and there is one omission in the UK case, which cannot be overcome as there have been no data on extension expenditures since free public extension was ended in 1988. It is not possible to determine the effect this omission has on estimated elasticities for public and private technology generation. In discussing attribution problems, Alston and Pardey (2001) suggest that private R\&D and extension may both be positively correlated with public R\&D. Nor will it ever be possible to collect data on the extension costs of the hundreds of farm management consultancy companies that have replaced the public system. So, one challenge is to find another way of including extension in the model, perhaps by modeling the gap between trial plot and farm yields, which is usually taken to be a measure of the effectiveness of the extension system.

Fitting any model over a period gives coefficients that are an average for that period. If more detailed data can be discovered, the assumption that the lag coefficients are constant should be relaxed. First, the targeting of R\&D tends to change over time and in the UK there was some change toward targeting public interest issues, such as environment, animal welfare, and food safety, rather than productivity growth. The 
impacts of actual TFP enhancing R\&D would thus be larger, if some of the R\&D included here is being targeted elsewhere.

The other related implicit assumption is that the R\&D lag length stays the same over the period. The claims made for biotechnology included the shortening of the research lag. One trait from a plant can be incorporated without waiting for the crop to grow and bringing in all manner of other unwanted traits that then have to be bred out, if conventional methods were used. Set against this the increasing length of the regulatory lags, as checks have become more thorough and the lag length could be longer or shorter over time. These types of issues need to be attacked separately and the information imposed in this type of lag modeling. Expecting to discover more by fitting the lags in even more complex ways must hit diminishing returns.

\section{Comparing ROR to R\&D}

One reason for modeling the shape of the lag is that it has just as much impact on the rate of return as do lead time and lag length. Higher returns will be shown by the more positively skewed distributions since the bulk of the productivity effects occur early on and thus their value is less eroded by discounting. Table 7 reports the sum of the elasticities of TFP with respect to R\&D for all the models that fit the best and the marginal internal rates of return. The way in which these are calculated can be found in numerous publications, but these follow exactly the methodology explained in Thirtle and Bottomley (1989). The first two results are for single-year lags and it is clear that if a single peak year is used it attracts a similar elasticity to that of a complete lag structure, such as the third result, which is the constrained PDL. That for the trapezoid is not strictly comparable. It is slightly lower than the PDL because of the longer lag period of 35 years. The range of the RORs across these models is even smaller, being only from $22 \%$ to $27 \%$, which conforms well with expectations based on surveys of past studies. For example, Alston and Pardey (2001) argue that the very high ROR that were common in the early literature were caused by short series truncating the lag structure.

Table 7

ROR to public R\&D expenditures

\begin{tabular}{|c|c|c|}
\hline Lag structure & $\begin{array}{l}\text { ¿ Significant } \\
\text { R\&D elasticities }\end{array}$ & ROR, \% \\
\hline UK R\&D $D_{-12}$ & 0.1393 & 22 \\
\hline UK R\&D $D_{-12,}$ R\&D $D_{-24}$ & 0.1264 & 23 \\
\hline $\begin{array}{l}\text { PDL 2nd degree, } 25 \text { lags, start } \\
\text { and end constrained to zero }\end{array}$ & 0.1951 & 27 \\
\hline Trapezoid with 35 lags & 0.1717 & 21 \\
\hline $\begin{array}{l}\text { PDL. 2nd degree, } 25 \text { lags, no } \\
\text { constraints }\end{array}$ & 0.2876 & 34 \\
\hline $\begin{array}{l}\text { Beta distribution UK R\&D with } \\
25 \text { lags only }\end{array}$ & 0.1092 & 15 \\
\hline $\begin{array}{l}\text { Beta, R\&D with } 25 \text { lags + } \\
\text { mechanical \& chemical patents } \\
+ \text { farm size }\end{array}$ & 0.3153 & 34 \\
\hline PDL 4th degree, 25 lags, bimodal & 0.5207 & 71 \\
\hline $\begin{array}{l}\text { PDL 4th degree, } 25 \text { lags, } \\
\text { Unimodal }\end{array}$ & 0.2335 & 26 \\
\hline
\end{tabular}


The next step was to relax the priors, with the unconstrained second-degree polynomial. The greater flexibility raises the elasticity to 0.29 and the ROR to $34 \%$. The beta distribution without the other explanatory variables allowed the distinct negative skew, which combined with the low elasticity of 0.11 , led to a ROR of only $15 \%$. This result can probably be disregarded, since when the patent variables are added the elasticity rises to 0.32 and the ROR to $34 \%$. The highest elasticity and ROR result from the bimodal model, which gives a ROR of $71 \%$, but the distribution of funding between short- and long-run projects would need to be known to make a more precise ROR calculation in this case. The last result, for the unimodal fourth-order PDL returns to the normal range, with a ROR of $26 \%$, which on the basis of the model selection criteria would be the best choice with the improved but probably still faulty data that we have.

\section{Conclusions}

This article outlines the demise of TFP growth in UK agriculture since the early 1980s and explains almost all of the variance in TFP with public R\&D expenditures, mechanical and chemical patents, which represent the private sector and farm size. Public R\&D, private patents, and farm size were shown to explain all but $2 \%$ of the variance in TFP, which is a vast improvement on the past work on R\&D and productivity in the UK. However, better data and longer series make for more stringent time series tests to ensure that the equations are valid. The tests here establish the time series properties of the variables, find cointegrating regressions and vectors and establish that Granger causality runs from the technology variables to TFP and not the reverse.

Then, the R\&D lag is modeled, with a view to imposing few priors and allowing model specification and testing of the lead time and the lag length and shape to be done together. The first contribution of this article is to show that the most commonly used lag structures, which are the second-degree PDL and the trapezoid, even though yielding significant elasticities do not fit the data very well. The PDL cannot represent the data if the lag is skewed and the trapezoid being used appears to have the wrong skew for the USA and the UK.

The beta distribution is preferable, but the article then shows that the R\&D lag cannot be fitted independently of the private sector patent data. Since the private sector now spends more than the public sector and the two efforts are interrelated this is hardly surprising, but the direction of the effect is robust and unexpected. Including the shorter-run patent variables could be expected to reduce the impact of the public R\&D lag in early years. Instead, it very substantially increases it, raising issues of the substitutability or complementarity of public and private R\&D.

The third contribution is equally hard to reconcile with the commonly imposed lag structures, as the R\&D lag tends toward bimodality in some models. It is possible that the type of near market R\&D still done by DEFRA, which verges on extension, accounts for the first of the twin peaks, while the second, with a gestation period of over 20 years, results from the quite basic R\&D undertaken by the Biotechnology and Biological Science Research Council. Between the twin peaks, at the point where 
second-degree polynomial and trapezoid lags estimate the highest weights, there is no evidence of and impact of R\&D on productivity, in several of the models fitted.

The conventional models may be at odds with the data and give poor estimates of the ROR to R\&D, but definitive statements are foolhardy. Griliches (1994) points out that the data are the constraint is undoubtedly still valid, but more theory as well as more data are required for better estimates. But the theory should not lead to stronger priors being imposed on the data. Instead, it should be an attempt to break up and separate the many factors that spill into TFP change. It is a function of basic and applied, public and private, domestic and foreign $\mathrm{R} \& \mathrm{D}$, extension, returns to scale, changes in crop and animal mix, the weather, and no doubt many other influences like trade. It is not surprising that reliable estimates are hard to obtain with so much going on, especially when even central issues like the interrelationships between public and private activity are so poorly understood.

\section{Footnotes}

1 For most of this period Imperial Chemical Industries (ICI) was one of the leading UK companies. It did most of its research in the UK, which was only $10 \%$ of its market and the rest in California, because of the availability of quality researchers (Thirtle et al., 1997). Typically, patents would be registered in all countries of interest. 2 The long lags lead to slightly different start and end dates in these models. The estimation period is kept as long as possible by extrapolating series for a few years when this does not change the results significantly. The exact periods are recorded in the data appendix. The R\&D data from Thirtle et al. (1998) was used to extend the series.

\section{References}

- Alston, J. Pardey, P., 2001. Attribution and other problems in assessing the returns to agricultural R\&D. Agric. Econ. 25, 141-152.

- Alston, J., Pardey, P., Smith, V., 1999. Paying for Agricultural Productivity. Johns Hopkins Press, Baltimore, MD .

- Alston, J., Chan-Kang, C., Marra, M., Pardey, P., Wyatt, T., 2000. Metaanalysis of rates of return to agricultural R\&D: ex pede herculem? Research Report No. 113, Washington DC : IFPRI. June.

- Chavas, J., Cox, T. L., 1992. A nonparametric analysis of the influence of research on agricultural productivity. Am. J. Agric. Econ. 74, 583-591.

- Engle, R. F., Granger, C. W. J., 1987. Cointegration and error correction: representation, estimation and testing. Econometrica 55, 251-276.

- Gilbert, C. L., 1990. Professor Hendry's econometric methodology. Chapter 13. In: C. W. J. Granger (Ed.). Modeling Economic Time Series. Clarendon Press, Oxford .

- Griliches, Z., 1994. Productivity, R\&D and the data constraint. Am. Econ. Rev. 84, 1-23. Reprinted in Economic Growth in the Long Run: A History of Empirical Evidence, vol. III, Bart van Ark, ed., Elgar, 1997. 
- Huffman, W. E., Evenson, R. E., 1989. Supply and demand functions for multiproduct U.S. cash-grain farms: biases caused by research and other policies. Am. J. Agric. Econ. 71, 761-773.

- Huffman, W. E., Evenson, R. E., 1992. Contribution of public and private science and technology to US agricultural productivity. Am. J. Agric. Econ. 74, 751-756.

- Huffman, W. E., Evenson, R. E., 2006. Science for Agriculture: A Long-Term Perspective, Second edition. Blackwell Publishing, Ames, IA .

- Johansen, S., 1988. Statistical analysis of cointegrating vectors. J. Econ. Dynam. Contr. 12, 231-254.

- Judge, G., Griffiths, W., Hill, R., Lutkepohl, H., Lee, T., 1985. The Theory and Practice of Econometrics, Second edition, John Wiley \& Sons, New York

- Khatri, Y. J., 1994. Technical change and the returns to research in UK agriculture, 1953-1990. Unpublished PhD dissertation, University of Reading, England .

- Khatri, Y., Thirtle, C., 1996. Supply and demand functions for UK agriculture: biases of technical change and the returns to public R\&D. J. Agric. Econ. 47, 338-354.

- Khatri, Y. J., Thirtle, C., 2000. Cointegration and modeling the length and shape of the research lag. Chapter 10. In: C. Thirtle, J. van Zyl, N. Vink (eds.), South African Agriculture at the Crossroads: An Empirical Analysis of Efficiency, Technology and Productivity, Macmillan, Basingstoke .

- Maddala, G. S., 1977. Econometrics. John Wiley, Chichester, UK .

- Mullen, J., Cox, T., 1995. The returns from research in Australian broadacre agriculture. Aus. J. Agric. Econ. 39, 105-128.

- Oehmke, J. F., Schimmelpfennig, D. E., 2004. Structural change in the research-productivity relationship. J. Prod. Anal. 21, 297-315.

- Schimmelpfennig, D. E., Thirtle, C., 1994. Cointegration, and causality: exploring the relationship between agricultural R\&D and productivity. J. Agric. Econ. 45, 220-231.

- Schimmelpfennig, D. E., Thirtle, C., 1999. The internationalization of agricultural technology: patents, $R \& D$ spillovers and their effects on productivity in the European Union and United States. Contemporary Econ. Pol. 17, 457-468.

- Schmidt, P., 1974. An argument for the usefulness of the gamma distributed lag model. Int. Econ. Rev. 15, 246-250.

- Thirtle, C., Bottomley, P., 1989. The rate of return to public sector agricultural R\&D in the UK, 1965-80. Appl. Econ. 21, 1063-1086.

- Thirtle, C., Palladino, P., Piesse, J., 1997. On the organisation of agricultural research in Great Britain, 1945-94: a quantitative description and appraisal of recent reforms. Res. Pol. 26, 557-576.

- Thirtle, C., Bottomley, P., Palladino, P., Schimmelpfennig, D. S., 1998. The rise and fall of public sector plant breeding in the UK: a recursive model of basic and applied research, and diffusion. Agric. Econ. 19(1-2), 127-143.

- Thirtle, C., Lin, L., Holding, J., Jenkins, L., Piesse, J., 2004. Explaining the decline in UK agricultural productivity growth. J. Agric. Econ. 55, 343-366.

- Tsurumi, H., 1971. A note on gamma distributed lags. Int. Econ. Rev. 12, 317-323.

- Vogelvang, B., 2005. Econometrics: Theory and Applications with Reviews. Chapter 12. Pearson Education, Harlow, Essex. 